\title{
Digital game-based learning of information literacy: Effects of gameplay modes on university students' learning performance, motivation, self-efficacy and flow experiences
}

\author{
Di Zou, Ruofei Zhang \\ Department of English Language Education, The Education University of Hong Kong, New Territories, \\ Hong Kong SAR
}

\author{
Haoran Xie \\ Department of Computing and Decision Sciences, Lingnan University, Tuen Mun, Hong Kong SAR
}

\section{Fu Lee Wang}

School of Science and Technology, The Open University of Hong Kong, Kowloon, Hong Kong SAR

\begin{abstract}
Information literacy (IL) is important for university students. In this research, we developed a digital role-playing game to enhance students' learning of IL and investigated the effects of gameplay modes on their learning performance, motivation, self-efficacy and flow experiences. A total of 90 students participated in the study and played the game in collaborative, competitive and solo modes. Their IL knowledge was measured through a post-test after they completed the game and associated exercises. Their motivation, selfefficacy and flow experiences were evaluated through a questionnaire survey. The results indicated statistically significant effects of the gameplay modes on the students' learning performance, motivation, self-efficacy and flow experiences. The solo mode was inferior to the other two in all four aspects. The collaborative mode significantly outperformed the competitive mode in terms of enhancing learning performance and flow experience, while the competitive mode was significantly better in terms of promoting self-efficacy. These two modes were similarly effective in the dimension of motivation. Based on the results, we suggest that students play games in the collaborative or competitive modes when conditions permit. We also advise teachers to provide students with rich opportunities for discussion, collaboration and interaction and believe that an appropriate competitive atmosphere is important.
\end{abstract}

\section{Implications for practice or policy:}

- Teachers can help students to improve their IL learning performance, motivation, selfefficacy and flow experiences by encouraging them to play games in collaborative or competitive modes.

- Teachers can increase students' engagement in learning by adding collaborative and competitive elements in teaching and learning.

- Teachers can enhance students' knowledge comprehension and consolidation by integrating discussion, collaboration and interaction in classroom activities.

Keywords: educational game, information literacy, flow state, self-efficacy, competition, quantitative

\section{Introduction}

Information literacy (IL) refers to a set of abilities to "recognize when information is needed" and "locate, evaluate, and effectively use the needed information" (American Library Association, 2000, p. 15). Under this umbrella, it involves the abilities to determine the need for information, access the needed information, evaluate the quality, authenticity and credibility of information, incorporate information into prior knowledge and understand and use information contextually, effectively and ethically (Koltay, 2011). Several studies have been conducted to investigate students' IL development. Johnston (2010) asked students to learn IL through an e-learning system that included tutorials and IL learning tasks. The results showed that the proposed learning approach was very effective in enhancing students' understanding of IL concepts. Kong (2014) designed a 13-week Integrated Humanities course into which IL teaching was 
woven. A total of 107 students learned the course with tablets. The results of three tests showed that the course significantly enhanced students' IL development. Derakhshan et al. (2015) interviewed 15 educators of IL and found that this discipline could be taught through lectures, workshops and modules. The main pedagogical practices consisted of supporting students' selection of research topics, helping them identify and access their needed information and developing a query on their essays.

Moreover, many researchers and institutions have implemented educational games to help students develop IL in higher education. Markey et al. (2008) designed an online board game in which players sought and used digital library resources to answer questions on scholarly topics. A total of 49 university students played the game to learn IL skills and concepts. The results indicated the overall effectiveness of the proposed game and revealed several game features that may influence students' learning outcomes, including feedback, challenge functionality and the themes of the games. Furthermore, Utah Valley University developed two games, Get a Clue and Library Craft, to introduce the university's physical and digital libraries to their students (Smith \& Baker, 2011). Most students who learned with the game reported positive learning outcomes and experiences in a questionnaire survey. In the study by J. Wu et al. (2015), university students were required to play a series of 10 games, Wisdom Town, which taught database knowledge. The results revealed that most students considered digital game-based learning (GBL) an effective approach to IL development. Additionally, Guo et al. (2017) required 150 university students to learn IL knowledge by playing a role-playing game, Library Escape. In the game, the main character was locked in a library and required to complete six IL learning tasks for escaping therefrom. The results indicated that the participants had overall high levels of attention, satisfaction and affective enjoyment and perceived usefulness of the game.

However, most studies on GBL for IL development have focused on whether digital games were effective in terms of promoting students' learning outcomes and motivation, while little research has been conducted to explore other aspects of GBL. Thus, this research aimed to investigate university students' learning performance, motivation, self-efficacy and flow experiences of playing a digital game in diverse modes. These four learning-related dimensions were selected as most previous research on computer-assisted learning focused on them (Su \& Zou, 2020; Zhang \& Zou, 2020; Zou et al., 2020). For example, M. P. Chen et al. (2020) investigated students' learning performance and motivation in augmented realityenhanced theme-based contextualised English learning. M. P. Chen et al. (2019) investigated students' learning performance, motivation and self-efficacy in a context-aware ubiquitous learning environment. Hwang et al. (2020) investigated the effects of a multi-level concept mapping-based question-posing approach on students' learning performance and experience.

\section{Literature review}

\section{GBL}

GBL has been receiving increasingly more academic attention in recent years (Guo et al., 2017; Zou, 2020). The effects of GBL have been extensively experimented in higher education and reported to be overall positive on prompting learner motivation, raising the sense of control over learning and enhancing learning performance and perceptions (e.g., Chen \& Wang, 2018; Troussas et al., 2020; Yukselturk et al., 2018). Moreover, by providing a playful learning environment, educational games may lead students to enjoy learning, feel comfortable with multiples challenges during the process and overcome these challenges with concentration, confidence and patience (Romero et al., 2017), which are essential for higher education in developing lifelong learners (Liu et al., 2020; Sharples, 2000).

Despite the overall effectiveness of digital GBL (Annetta, 2010; Guo et al., 2017; Liu et al., 2020; Yukselturk et al., 2018), educational games are not always successful (Young et al., 2012). Without appropriate design and development, they may be distracting, boring and of little educational value (DiNardo \& Broussard, 2019; Young et al., 2012). Prior literature has reported five crucial factors in successful educational games:

- Fantasy: Games should afford a fictional universe that includes interesting storylines, engaging scenarios and fascinating settings (Jemmali et al., 2018).

- Identity: Players should be the main characters in games (Annetta, 2010). 
- Interactivity: Players could communicate with other players or computerised non-player characters (NPCs) (Annetta, 2010; Perttula et al., 2017).

- Rewards: Players should be given rewards or scores when they have completed or well-performed a task in games (Park et al., 2019; Ronimus et al., 2014).

- Knowledge improvement: Games should help players develop target knowledge and skills to reach the learning goals (Annetta, 2010; Fu et al., 2009).

\section{Competition in GBL}

When competition is involved in GBL, learners attempt to perform better than others to win the game (Chen et al., 2018; Hong et al., 2009). Many researchers believe that competition in GBL is conducive to the improvement of students' learning performance, engagement, motivation and persistence in learning activities (C. H. Chen et al., 2020; S. Y. Chen \& Chang, 2020; Kollöffel \& De Jong, 2016). Concerning GBL of IL, Cagiltay et al. (2015) designed a competitive GBL system for IL education, where learners can view the scores and rankings of themselves and their peers from a leader board during the learning process. The results showed that the students who learned in the competition mode significantly outperformed those who did not in the post-test.

Competition is also an effective game element for encouraging students to actively learn and accept challenges (Hwang \& Chang, 2016; Zou et al., 2018). Wei et al. (2018) found that competitive gaming and personalised assistance enhanced students' immersion experience and vocabulary learning efficiency but reduced their anxiety. Moreover, Plass et al. (2013) argued that the students who had competitive gameplay achieved better learning outcomes than those who had individual and collaborative gameplay. However, C. H. Chen et al. (2018) identified no significant differences in terms of their flow experience between the participants who conducted competitive GBL and those who did not. Flow refers to a state of complete immersion or engagement in an activity (Pearce et al., 2005). C. H. Chen et al. (2018) believed that the integration of competition into GBL might result in extraneous distractions, compromising the positive effects of increased engagement and control in learning, and consequently influenced students' flow experience.

\section{Collaboration in GBL}

When collaboration is involved in GBL, learners exchange ideas and information and support each other to reach their common goals (Hsiao et al., 2014). Previous research has indicated that collaboration in GBL leads to increased engagement in learning (J.-H. Wu et al., 2010) and enhanced learning performance (Kuo et al., 2012; Zurita et al., 2005). Nevertheless, collaboration per se does not necessarily result in effective learning. Sung and Hwang (2013) pointed out that appropriate scaffolding is essential for effective collaborative GBL.

As collaboration promotes social interactions, it appears effective in terms of enhancing communication and peer relationships (Eow et al., 2010). In collaborative learning environments, students are also likely to perceive high satisfaction, enjoyment and usefulness of GBL (Plass et al., 2013; Shiue \& Hsu, 2017). Moreover, Admiraal et al. (2011) believed that collaboration in GBL is conducive to students' sense of immersion in learning. Kiili et al. (2012) also reported that collaboration increases students' sense of control, awareness of goals and skills to deal with challenges in game. However, C. H. Chen and Law (2016) found that collaboration might lead to decreased motivation when students lack collaboration and communication skills.

\section{Limitations of previous research on GBL of IL}

Although several studies have been conducted to investigate GBL of IL, most of them focused on whether games led to effective learning or increased students' learning motivation. Little research has been conducted to investigate the possible effects of gameplay modes on GBL of IL. Thus, it is uncertain how solo, competitive and collaborative gameplay modes might influence students' learning performance and motivation.

Moreover, most previous studies only examined students' learning performance and motivation, while other dimensions have rarely been explored. Considering that students' self-efficacy plays a key role in 
their development and that flow experience is important for GBL, a study on the effects of an IL learning game on students' self-efficacy and flow experience seems necessary.

Therefore, this research aimed to investigate university students' learning of IL through playing a digital game in solo, competitive and collaborative modes. Their learning performance, motivation, self-efficacy and flow experiences were examined to address the following research questions:

- Do gameplay modes influence university students' learning performance?

- Do gameplay modes influence university students' motivation?

- Do gameplay modes influence university students' self-efficacy?

- Do gameplay modes influence university students' flow experiences?

\section{An IL learning game based on flow theory}

The design of our IL game was mainly based on Csikszentmihalyi's (2014) flow theory. Flow theory suggests that when individuals are deeply involved in specific activities, they will become immersed in an optimal experience, termed as a flow state. In a flow state, individuals concentrate on the contents and tasks at hand, forget all irrelevant issues and time passing and have great enjoyment (Annetta, 2010; Hsu, 2017; Perttula et al., 2017). Engagement in educational games may lead to a flow state, which may enhance learning efficiency by promoting learner motivation and improving learning experience (Barzilai \& Blau, 2014; Hsu, 2017). To help players enter a flow state, educational games should afford them to have goals and rules, feedback and a sense of control (Annetta, 2010; Csikszentmihalyi, 2014; Hsu, 2017; Perttula et al., 2017). Specifically, goals and rules refer to lucid and specific explanations about the goals and ways to reach the goals at the beginning (Csikszentmihalyi, 2014; Perttula et al., 2017). Feedback is mainly about the evaluation of the players' performance in tasks (Annetta, 2010; Kiili, 2005). Sense of control relates to players' feeling of autonomy of deciding their behaviours and progress (Hsu, 2017; Liu et al., 2020).

We developed this game using the RPG Maker MV, based on three prerequisites of flow experience and the five factors of successful educational games. As shown in Figure 1, students engage in our educational game by interacting with the NPCs as the main character in the setting of fantasy. Through acting as the main character, learners obtain their identity in the virtual environment. Through interactivity with the NPCs, learners achieve knowledge improvement and receive rewards for their completion of learning tasks. The materials for IL knowledge development consist of (a) warm-up questions that provide players with previews of what they will learn subsequently; (b) instructional videos that teach players IL knowledge and skills; and (c) formative assessments of players' knowledge of what they have learned from the videos.

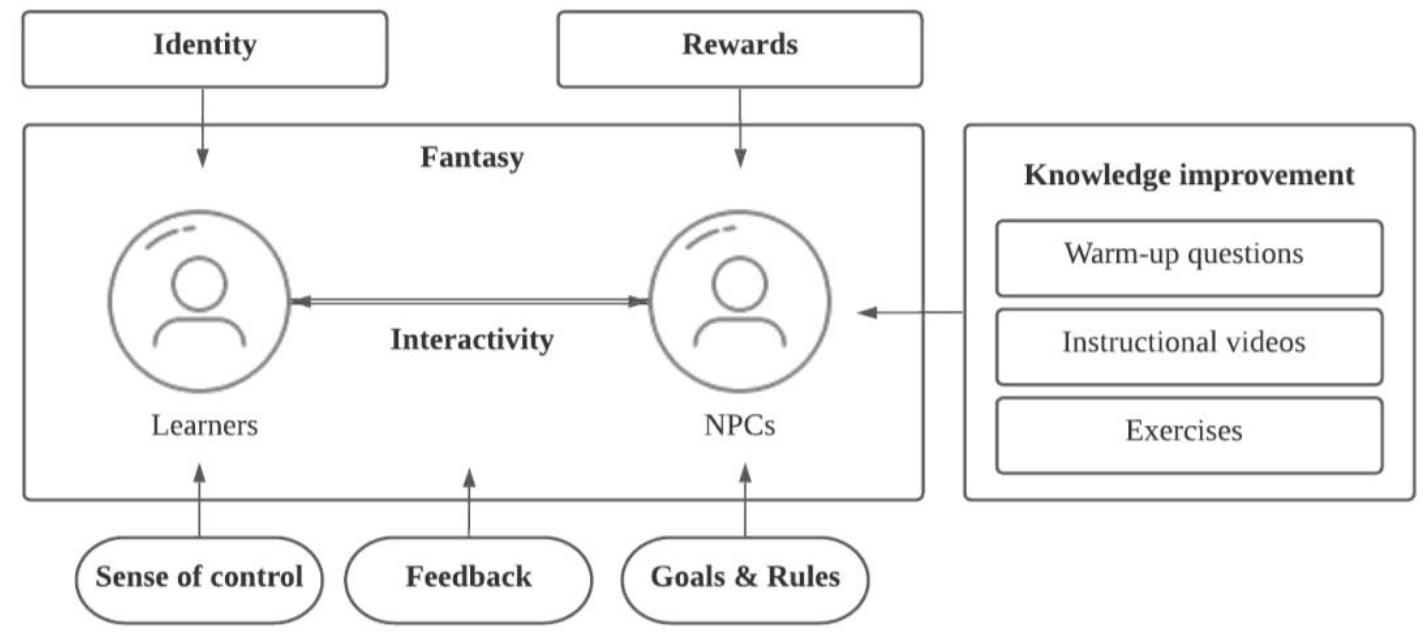

Figure 1. The system structure of the IL learning game 
Table 1 illustrates the game design. In the beginning of the game, an NPC explains the setting, goal and rules of the game. During gameplay, the NPCs explain the detail goals and rules of different learning tasks at the beginning of each learning task. After explanations, the NPCs ask players whether they fully understand the goals and rules (i.e., "Have you understood your goal and tasks in this journey?"); they repeat the explanations if players give negative reply (i.e., "Errrrr, I don't think so."). The players take control of their movements, interactions with the NPCs and the pace of the game. They can decide whether to watch a video right now, to watch it again, to stop the gameplay or to move to the next stage of learning. When the players submit their answers to the associated exercises to the system, the NPCs provide immediate feedback. Specifically, when players submit wrong answers, the NPCs provide feedback on the answers and ask them to try again; and when they submit wrong answers in consecutive attempts, the NPCs provide encouragement. When players submit correct answers, the NPCs provide feedback for compliments and rewards.

Table 1

Game design based on the three prerequisites of flow experience

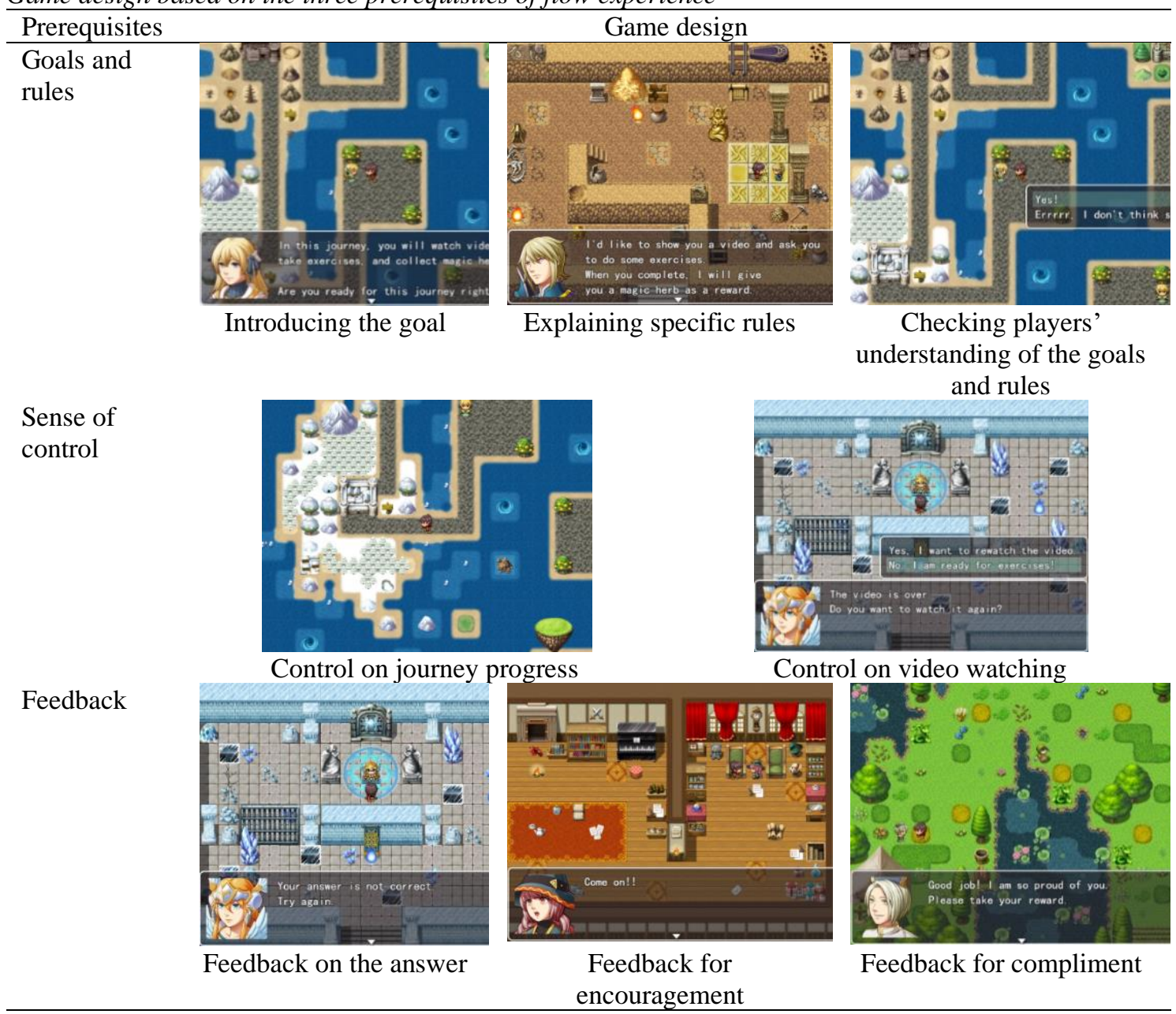




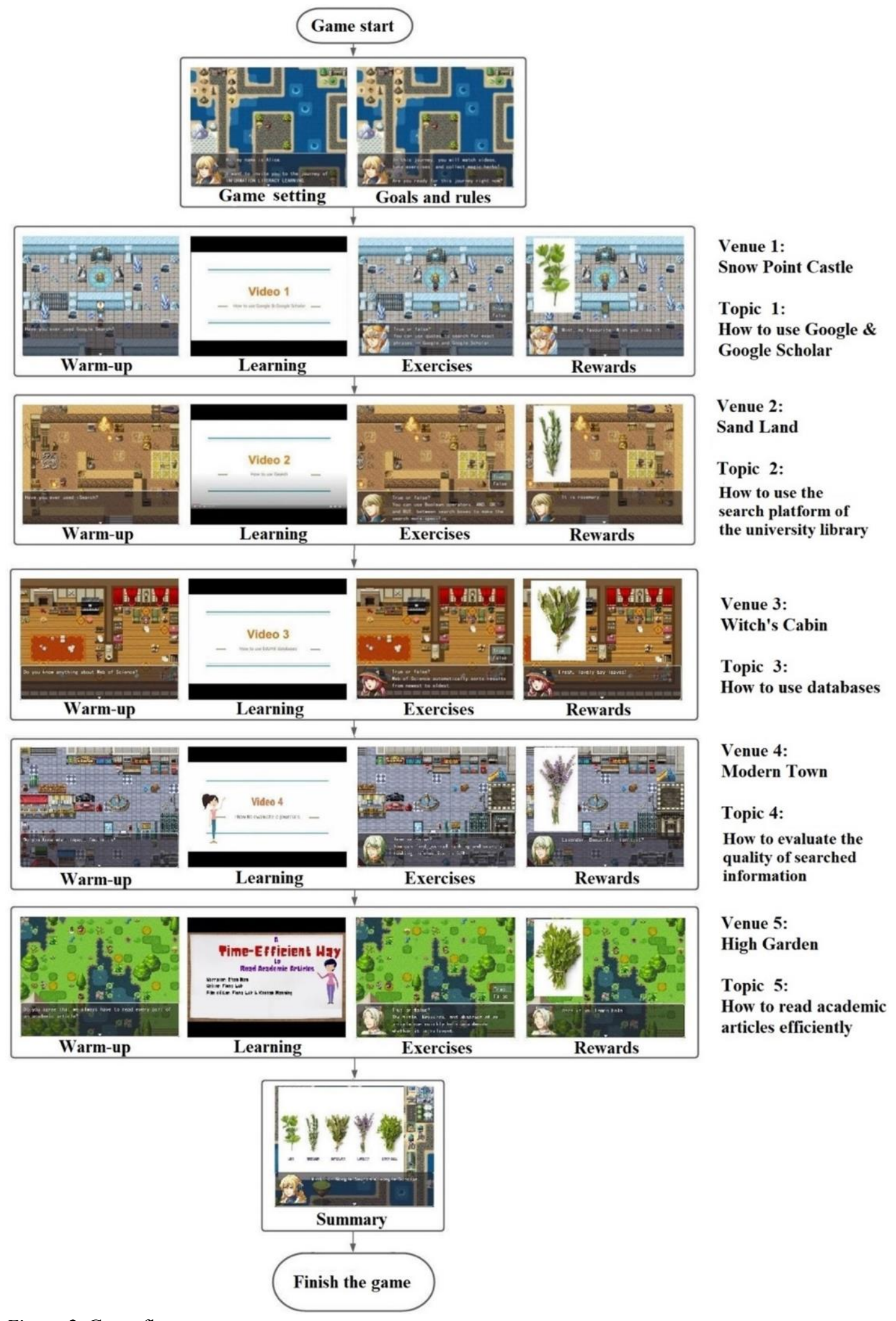

Figure 2. Game flow 
Figure 2 shows the whole map of the gaming content and the locations of diverse tasks in the map. Figure 3 shows the map of the journey, which consists of five venues corresponding to five topics of IL learning, specifically (a) how to use Google and Google Scholar, (b) how to use the search platform of the university library, (c) how to use databases, (d) how to evaluate the quality of searched information and (e) how to read academic articles efficiently. These are all important IL topics for university students.

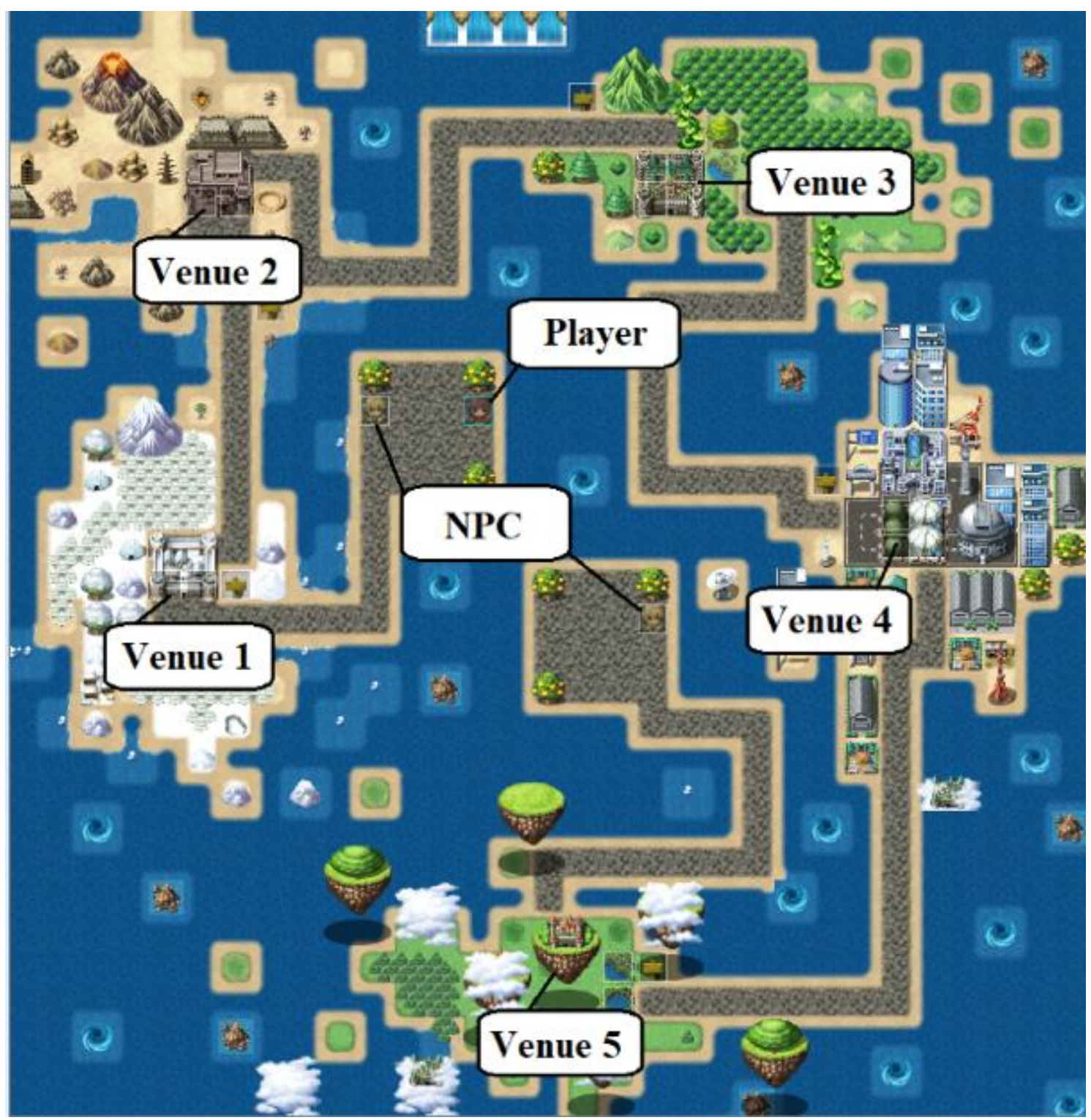

Figure 3. The whole map of the journey

Following the map, players enter the five venues in order. Figure 4 shows the interface of a learning task. In each venue, players watch one instructional video and complete two to four associated exercises. The exercises are true-false and multiple-choice questions that check players' understanding of the video content. When players complete all exercises of one scene in one venue, the NPCs give them a "magic herb" as a reward and encourage them to move on to the next stage of learning. After completing all learning tasks in the five venues, an NPC shows all the rewards that players have obtained, helps them reflect on their learning process and makes a summary of it. 


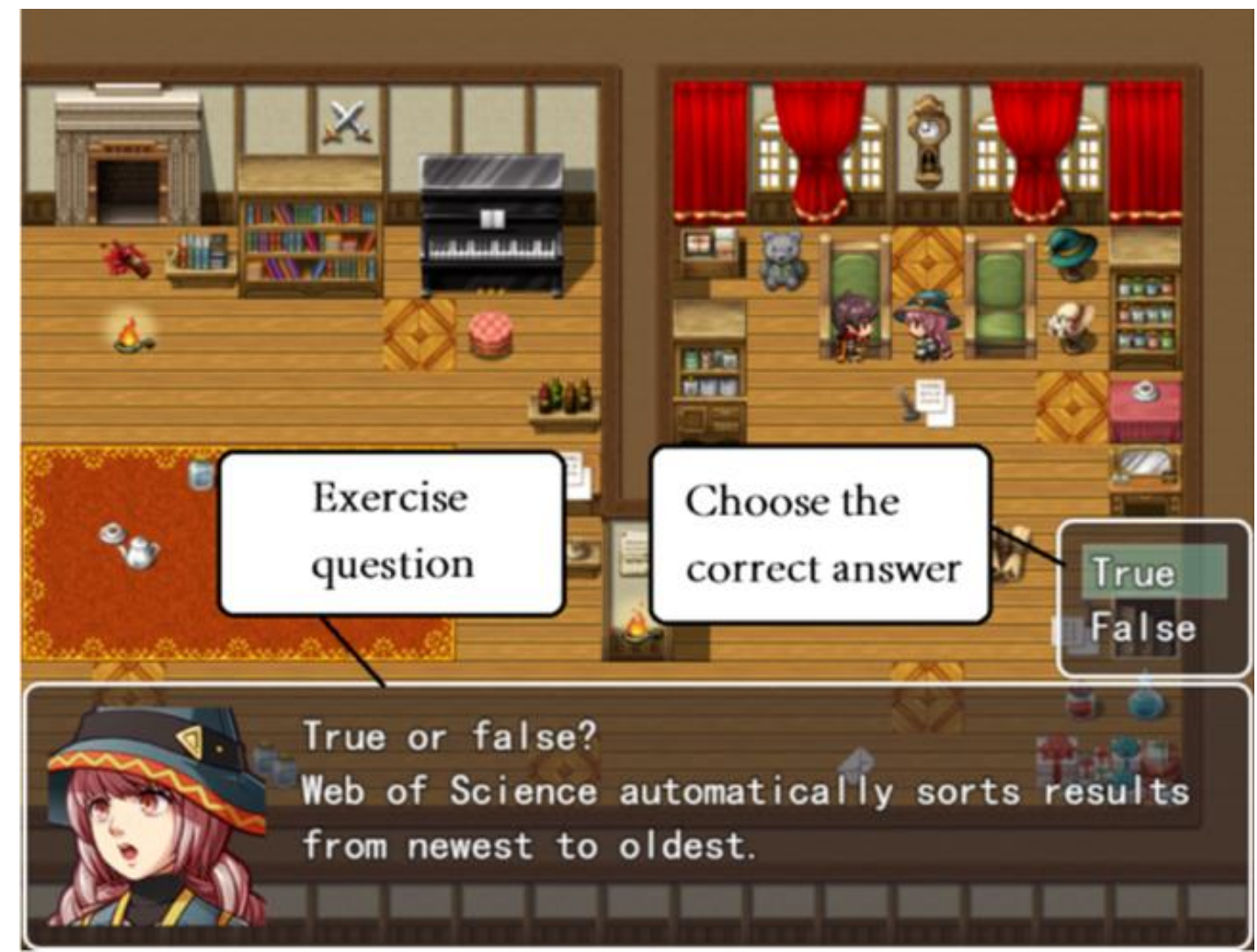

Figure 4. The interface of a learning task

\section{Method}

\section{Participants}

A total of 90 students, 81 girls and nine boys, in a local university in Hong Kong participated in the research. They were of similar ages and had similar education and cultural backgrounds. Also, they had never systematically and comprehensively learned IL before. We conducted a pre-test to investigate their prior IL knowledge, the results of which showed similar levels of IL knowledge of all participants. Moreover, the participants were registered in the same course, which aimed to teach them how to search for relevant academic resources, identify important information and write literature reviews. The same instructor who had 10 years of experience in teaching similar courses taught them. All students voluntarily participated in the study and knew that it would not influence their course grades. They were able to quit the project at any time. The research was conducted following relevant ethical guidelines and requirements of the university.

\section{Research design}

The instructor (one of the authors) conducted this project in normal class hours in 2020, beginning with a 15-minute briefing session to introduce the game and the project (see Figure 5). When all students were clear about the game, they participated in a pre-test that measured their prior IL knowledge and a prequestionnaire survey that evaluated their motivation and self-efficacy. This lasted for 20 minutes.

Subsequently, the students were randomly and equally assigned to three groups to complete the GBL of IL in three gameplay modes. The 30 students in Group 1 played the game in solo mode, in which all students played the game individually, and their performance was not compared against that of others in the same group. These students were asked to play the game at their own pace. In Group 2, the 30 students played the game in competitive mode. They played individually, but their performance was compared from both dimensions of pace and accuracy. In Group 3, the students played in collaborative mode, in pairs. Two players collaborated to complete the game at the pace of their team, and the performance of each pair was not compared with the performance of other pairs. 
After the treatment, the students participated in a post-test, which measured their IL knowledge after completing the GBL of IL and completed a post-questionnaire survey that evaluated their motivation, selfefficacy and flow experience. This lasted for 25 minutes. Moreover, we randomly selected 10 students from each group (30 in total) and interviewed them to collect data concerning their thoughts and feelings of the learning experiences. Additionally, the teacher kept an observation journal, to record what happened during the GBL process.

In sum, four major sets of data were collected, consisting of the students' scores in the pre- and post-tests; the questionnaire data about the students' motivation, self-efficacy and flow experience; the interview data of the students' thoughts and feelings of the GBL experiences; and the observation data of the GBL process. After marking the students' scores in the pre- and post-tests, all scores and the questionnaire data were entered into SPSS. The interview data of the students' thoughts and feelings of the GBL experiences and the observation data of the GBL process were analysed in the following way. We read all data thoroughly to obtain a holistic view first, and then focused on the data that highlighted the differences among diverse gameplay modes. After obtaining a systematic and comprehensive understanding of all data, we coded them independently and meticulously to identify possible factors that may influence the effectiveness of GBL and students' motivation, self-efficacy and flow experience. The coding results were also examined by two of our colleagues, with reference to the original data. This mixed method of research has been applied by many studies (e.g., Zou \& Xie, 2018, 2019).

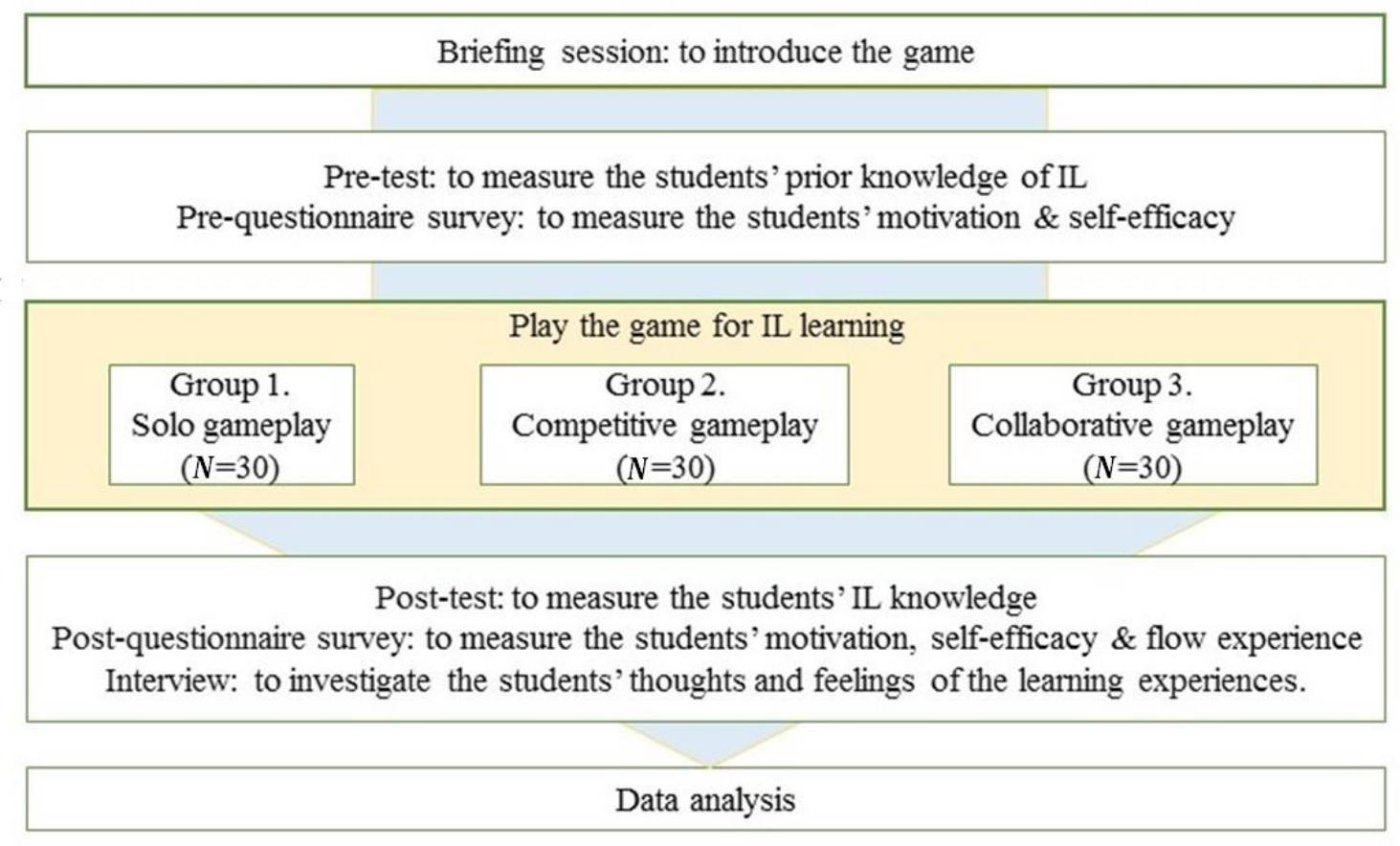

Figure 5. Research design

\section{Instruments}

The research instruments consisted of the pre- and post-tests, three questionnaires and interview questions. The pre-test consisted of 10 true-false questions and 10 multiple-choice questions with a full score of 100, five for each item. Items in the true-false questions included:

- "You can use an asterisk within quotes to specify unknown or variable words."

- "You can exclude a word from Google search by adding a minus sign in front of that word."

- "Journals with similar titles are of similar quality." 
Items in the multiple-choice questions included:

- "What can we do to make the search results more relevant? (a) Add NOT between feedback and system (b) Add OR between feedback and system (c) Add AND between feedback and system (d) Put feedback system in quotation marks."

- $\quad$ "If you want to search articles by Richard E. Mayer, what is the most efficient way to do so? (a) Search 'Richard E. Mayer' by author; (b) Search 'Richard E. Mayer' by title keyword; (c) Search 'Richard E. Mayer' by 'Subject begins with;' (d) Search 'Richard E. Mayer' by keyword."

The participants were asked to indicate their answers to the questions, and they received a score of five with a correct answer. The post-test was the same. The test items were developed by two domain experts and one teacher with 10 years of experience in teaching IL in higher education, with reference to Hsieh et al. (2014).

All three questionnaires applied the 5-point Likert scale, with 1 representing strongly disagree and 5 representing strongly agree. The motivation questionnaire was adapted from Wang and Chen (2010). It consists of six items, three of which are related to intrinsic motivation and three related to extrinsic motivation. Sample items include "I prefer tasks that challenge me so that I can learn new things.", "It is important for me to present my excellence to my family, friends and teachers." and "Getting a good grade is the most satisfying thing to me.”. Its Cronbach's alpha value was .86 .

The self-efficacy questionnaire was adapted from Pintrich et al. (1991). It consists of eight items, samples of which include "I am certain that I can master the skills being taught in this game.", "I am confident that I can understand the most difficult materials presented in the game." and "I am confident that I can understand the basic concepts taught in this game." The Cronbach's alpha value was .84 .

The flow experience questionnaire was adapted from Pearce et al. (2005). It also consists of eight items, samples of which include "I felt in control of what I was doing during the learning activity.", "During the game-based learning, time seemed to pass fast." and "I was completely immersed in this learning activity." The Cronbach's alpha value was .87.

Furthermore, examples of the guided questions for the follow-up interview of the participants' learning experience include "What do you think about this learning experience?", "Do you like the solo/competitive/collaborative gameplay mode? Why?" and "What do you think are useful or useless for your IL knowledge development?".

\section{Results}

\section{Influences of gameplay modes on learning performance}

A one-way ANCOVA was conducted to test whether statistically significant differences existed among the three gameplay modes in terms of enhancing the participants' learning performance, after controlling for their pre-test scores. The data could be analysed using the one-way ANCOVA as they passed the basic assumptions, including normal distribution, homogeneity of regression slopes and homogeneity of variance. Specifically, the results of the Levene's test of equality showed that the data were homogeneous in variances as the significance value was .86 .

As shown in Table 2, statistically significant differences existed among the three gameplay modes in terms of enhancing IL knowledge development, specifically $F(2,86)=14.38, p<.001$, partial $\eta^{2}=.25$. The means were respectively 84.33 for the solo gameplay mode, 87.50 for the competitive gameplay mode and 90.83 for the collaborative gameplay mode. The results of the pairwise comparisons also showed that the competitive gameplay mode was significantly more effective than the solo gameplay mode, but significantly less effective than the collaborative gameplay mode (see Table 3 ). 
Table 2

Summary of ANCOVA on learning performance

\begin{tabular}{lrrrrrrr}
\hline Gameplay mode & $N$ & $M$ & $S D$ & Adjusted $M$ & $S E$ & $F$ & $\eta^{2}$ \\
\hline Solo & 30 & 84.33 & 4.49 & 84.33 & .85 & $14.38^{* * *}$ & .25 \\
Competitive & 30 & 87.50 & 4.50 & 87.52 & .85 & & \\
Collaborative & 30 & 90.83 & 4.92 & 90.82 & .86 & & \\
\hline
\end{tabular}

$* * * p<.001$.

Table 3

Results of the pairwise comparisons of learning performance

\begin{tabular}{llrrr}
\hline (I) Gameplay mode & (J) Gameplay mode & $M D(I-J)$ & $S E$ & Sig. $^{a}$ \\
\hline Solo & Competitive & $-3.18^{*}$ & 1.20 & .03 \\
& Collaborative & $-6.48^{*}$ & 1.21 & .00 \\
\hline Competitive & Collaborative & $-3.30^{*}$ & 1.21 & .02 \\
\hline
\end{tabular}

a Adjustment for multiple comparisons: Bonferroni.

$* p<.05$.

\section{Influences of gameplay modes on motivation}

Another one-way ANCOVA was conducted to test whether statistically significant differences existed among the three gameplay modes in terms of improving the participants' learning motivation. Similarly, the data passed all basic assumptions. The results of the Levene's test of equality showed that the data were homogeneous in variances as the sig. value was 0.10 .

As shown in Table 4, statistically significant differences existed among the three gameplay modes from the perspective of the participants' learning motivation, specifically $F(2,86)=9.71, p<.001$, partial $\eta^{2}=.18$. The means were respectively 24.90 for the solo gameplay mode, 26.90 for the competitive gameplay mode and 26.13 for the collaborative gameplay mode. The results of the pairwise comparisons are shown in Table 5 , indicating that the competitive and collaborative gameplay modes were significantly more effective than the solo gameplay mode. However, no statistically significant differences existed between the competitive and collaborative gameplay modes.

Table 4

Summary of ANCOVA on learning motivation

\begin{tabular}{lrrrrrrr}
\hline Gameplay mode & $N$ & $M$ & $S D$ & Adjusted $M$ & $S E$ & $F$ & $\eta^{2}$ \\
\hline Solo & 30 & 24.90 & 2.23 & 24.91 & .32 & $9.71 * * *$ & .18 \\
Competitive & 30 & 26.90 & 1.56 & 26.89 & .32 & & \\
Collaborative & 30 & 26.13 & 1.33 & 26.13 & .32 & & \\
\hline
\end{tabular}

$* * * p<.001$.

Table 5

Results of the pairwise comparisons of learning motivation

\begin{tabular}{llrrr}
\hline (I) Gameplay mode & (J) Gameplay mode & $M D(I-J)$ & $S E$ & Sig. $^{a}$ \\
\hline Solo & Competitive & $-1.99 *$ & .45 & .00 \\
& Collaborative & $-1.22^{*}$ & .45 & .02 \\
\hline Competitive & Collaborative & .76 & .45 & .28 \\
\hline
\end{tabular}

a Adjustment for multiple comparisons: Bonferroni.

$* p<.05$.

\section{Influences of gameplay modes on self-efficacy}

Similarly, a one-way ANCOVA was conducted to test whether statistically significant differences existed among the three gameplay modes from the perspective of the participants' self-efficacy. The data could be analysed in this way as they passed all basic assumptions. The data were homogeneous in variances as the results of the Levene's test of equality showed that the significance value was .47. 
As shown in Table 6, statistically significant differences existed among the three gameplay modes from the perspective of the participants' learning motivation, specifically $F(2,86)=51.58, p<.001$, partial $\eta^{2}=.54$. The means were respectively 33.36 for the solo gameplay mode, 37.73 for the competitive gameplay mode and 34.93 for the collaborative gameplay mode. The results of the pairwise comparisons also indicated that the collaborative gameplay mode significantly outperformed the solo gameplay mode, while they were both significantly less effective than the competitive gameplay mode in terms of improving students' selfefficacy (see Table 7).

Table 6

Summary of ANCOVA on self-efficacy

\begin{tabular}{lrrrrrrr}
\hline Gameplay mode & $N$ & $M$ & $S D$ & Adjusted $M$ & $S E$ & $F$ & $\eta^{2}$ \\
\hline Solo & 30 & 33.36 & 1.86 & 33.33 & .31 & $51.58^{* * *}$ & .54 \\
Competitive & 30 & 37.73 & 1.31 & 37.74 & .31 & & \\
Collaborative & 30 & 34.93 & 1.96 & 34.94 & .31 & \\
\hline
\end{tabular}

$* * * p<.001$.

Table 7

Results of the pairwise comparisons of self-efficacy

\begin{tabular}{llrrr} 
(I) Gameplay mode & (J) Gameplay mode & $M D(I-J)$ & $S E$ & Sig. $^{a}$ \\
\hline Solo & Competitive & $-4.41^{*}$ & .44 & .000 \\
& Collaborative & $-1.61^{*}$ & .44 & .001 \\
\hline Competitive & Collaborative & $2.80^{*}$ & .44 & .000 \\
\hline
\end{tabular}

a Adjustment for multiple comparisons: Bonferroni.

$* p<.05$.

\section{Influences of gameplay modes on flow experience}

Concerning the questionnaire data about the students' flow experience, a one-way ANOVA was conducted. In contrast with the data of the participants' IL knowledge, motivation and self-efficacy, the flow experience data were collected only after the treatment. These data passed all basic assumptions as well and could be analysed in this way.

The descriptive statistics of the ANOVA test demonstrated that the collaborative gameplay mode $(M=$ $32.53, S D=1.63$ ) outperformed the other two modes from the perspective of the students' flow experience, and the competitive gameplay mode $(M=30.13, S D=2.11)$ was more effective than the solo gameplay mode $(M=28.43, S D=1.92)$. A summary of the results is presented in Table 8 . Statistically significant differences existed among the three gameplay modes, specifically $F(2,87)=35.23, p<.001$, partial $\eta^{2}=$ .45 . The results of the post hoc tests also showed significant differences among the three groups.

Table 8

Summary of ANOVA on self-efficacy

\begin{tabular}{|c|c|c|c|c|c|c|}
\hline & Type III SS & $d f$ & $M S$ & $F$ & Sig. & $\overline{\eta^{2}}$ \\
\hline Between groups & 254.60 & 2 & 127.30 & 35.23 & $.00 * * *$ & .45 \\
\hline Within groups & 314.30 & 87 & 3.61 & & & \\
\hline Total & 568.90 & 89 & & & & \\
\hline
\end{tabular}

Total 2 <.001.

Table 9

Results of the post hoc tests

\begin{tabular}{llrrr}
\hline (I) Gameplay mode & (J) Gameplay mode & $M D(I-J)$ & $S E$ & Sig. $^{a}$ \\
\hline Solo & Competitive & $-1.70^{*}$ & .49 & .001 \\
& Collaborative & $-4.10^{*}$ & .49 & .000 \\
\hline Competitive & Collaborative & $-2.40^{*}$ & .49 & .000 \\
\hline
\end{tabular}

a Adjustment for multiple comparisons: Bonferroni.

$* p<.05$. 


\section{Discussion}

\section{Influences of gameplay modes on learning performance}

The results of this research showed statistically significant effects of gameplay modes on IL development. The collaborative mode was the most effective in terms of promoting IL learning, followed by the competitive mode, and the solo mode was the least effective.

The interview and observation data also showed that in the collaborative gameplay mode, students discussed to enhance each other's understanding of the content of the instructional videos. This was very effective in terms of consolidating their thorough comprehension and deep memorisation of the target knowledge. Many students in this group even reported that they did not notice some information of the videos while watching them, and it was their partners who raised their awareness of these messages. Moreover, when they exchanged their understanding of the information with the partners, their knowledge was reorganised and consequently consolidated. However, this approach to learning through discussion was absent in the competitive and solo gameplay modes.

Nevertheless, in the competitive gameplay mode, students were motivated by a strong sense of competition; therefore, they were very focused while watching the instructional videos and doing the associated exercises. The observation data also showed that more students in this group took notes while watching videos, compared to the numbers of students who did so in the other two modes. Moreover, in the interview, these students explained that they took notes to avoid forgetting important details. That is, students in the competitive gameplay mode paid great attention to the content of the instructional videos and spent considerable efforts on achieving high accuracy while doing the associated exercises; therefore, this mode was more effective than the solo mode.

Having said that, the game-based approach to learning IL per se was interesting and conducive to effective learning; therefore, the students who learned in the solo gameplay mode also achieved satisfying performance in the post-test. Most of them also reported in the interview that they had learned much from the game and were confident that their IL knowledge had improved to a large extent.

Similarly, Hsiao et al. (2014) found that online collaborations and discussions in GBL could assist learners in knowledge development and idea creation, which consequently led to improvement of imaginative and creative thinking abilities. Moreover, Cagiltay et al. (2015) identified positive effects of competitive GBL on learning outcomes, as learners in competition tended to devote additional time and efforts to improving the accuracy of their answers to exercises. Our research results are consistent with these studies and provide further empirical support for them.

\section{Influences of gameplay modes on motivation}

The results indicated statistically significant effects of gameplay modes on IL learning motivation. The collaborative and competitive modes were significantly better than the solo mode. No significant differences existed between the collaborative and competitive modes.

This is likely because the collaborative mode involved discussions, while the competitive mode involved competition; and both discussion and competition placed positive influences on students' learning motivation with similar effects. Strong evidence can be identified from the interview data. Most students in the collaborative mode highlighted that the discussions made the learning process interactive, which were the most interesting and meaningful episodes of the learning experience for them. For the students in the competitive mode, it was the competition that spiced up the learning process, making it exciting and fun, as reported by most of them in the interview.

Many researchers also argued that collaboration in GBL increased learning motivation (e.g., Delucia et al., 2009; Sung \& Hwang, 2013; Zou et al., 2019). They found that students considered collaboration interesting and believed that synchronous communication and interaction created a strong social bond between them and their peers and improved their relationships (Delucia et al., 2009). Additionally, many studies found that competition played an important role in motivating students (e.g., Cagiltay et al., 2015; C. H. Chen et 
al., 2018). Hwang and Chang (2016) argued that competition mechanism in GBL could decrease learners' cognitive load but increase their motivation, and students regarded competitive GBL exciting.

\section{Influences of gameplay modes on self-efficacy}

The results indicated statistically significant effects of gameplay modes on students' self-efficacy. In this dimension, the competitive mode was the most effective, followed by the collaborative mode, and the solo mode was the least effective.

The students in the competitive gameplay mode felt that they independently completed the whole learning and achieved high accuracy in the associated exercises; therefore, they were knowledgeable about searching for information, using databases and evaluating information quality. They were confident that they had mastered relevant IL knowledge and skills well, as indicated by the interview data. Concerning the students in the collaborative mode, they collaborated for task completion and felt that they had learned a lot from the discussions and the whole learning process; therefore, their self-efficacy had improved greatly as well. The students in the solo mode, however, appeared less certain about their achievement of fully mastery of IL knowledge and skills.

Similar results have also been found by Sung and Hwang (2013), who argued that collaborative GBL guided learners to organise knowledge in their cognitive systems and share information with peers and that this process was conducive to the development of students' self-efficacy. Little research has discussed the possible influences of competition in GBL on students' self-efficacy, and this study plays a pioneering role in the field.

\section{Influences of gameplay modes on flow experience}

The results indicated statistically significant effects of gameplay modes on students' flow experience. In this dimension, the collaborative mode was the most effective, followed by the competitive mode, and the solo mode was the least effective.

The interview and observation data indicated that through collaboration and discussion, the students in the collaborative gameplay mode could encounter challenges and solve problems together, so they had the best flow experiences. Most students in this group also reported that they had total concentration, and their curiosity was aroused during the interaction while playing the game collaboratively. Moreover, they rarely sensed frustration as their partners could support them when they felt challenged.

The students in the competitive mode were to some extent driven by their strong sense of competition to fully focus on the game, and this focused attention led to deep engagement. However, some participants pointed out that the competition atmosphere sometimes resulted in extraneous distractions or anxiety when they encountered challenges.

The students in the solo mode, however, had neither the benefits of peer support nor a sense of competition, so their flow experiences were comparatively less satisfying than those in the collaborative and competitive modes. Nonetheless, the students in the solo mode reported generally positive flow experiences as the IL learning game of this research was designed and developed based on flow theory. The goals and rules were clear. The players had a sense of control and were provided with immediate feedback.

Although the literature on the effects of collaboration on flow experiences remains sparse, some articles have suggested a positive connection between collaboration and students' flow experiences in GBL. Admiraal et al. (2011) developed a collaborative GBL programme for history education, with which students completed a series of learning tasks in teams. The results showed that collaboration in game effectively enhanced students' immersion in a flow state. Kiili et al. (2012) also reported that collaboration enhanced students' flow experiences, increased their sense of control and awareness of goals and assisted them in dealing with challenges in game. However, research on competition in GBL has reported generally neutral or negative results. C. H. Chen et al.'s (2018) integration of competition into GBL might result in extraneous distractions. C. H. Chen et al. (2019) also pointed out that competition may place negative effects on learners' flow experiences in GBL as learners in competition may be distracted from learning by winning. 


\section{Conclusion}

In this research, we developed a digital role-playing game to enhance university students' IL learning and investigated the effects of gameplay modes on students' learning performance, motivation, self-efficacy and flow experiences. The results indicated that the solo mode was inferior to both collaborative and competitive modes in all four aspects. The collaborative mode significantly outperformed the competitive mode in terms of enhancing learning performance and flow experience, while the competitive mode was significantly better in terms of promoting students' self-efficacy. These two were similarly effective in the dimension of learning motivation.

Based on the results of this research, we suggest that students play games in the collaborative or competitive modes when conditions permit, as collaboration and a sense of competition can largely increase engagement in learning, and focused attention is conducive to effective learning. We also advise teachers to provide students with rich opportunities for discussion, collaboration and interaction, as these elements play important roles in leading to thorough comprehension and successful consolidation of target knowledge and skills. Moreover, discussions can help students reorganise what they have learned and lead to deep memorisation of the target knowledge. Furthermore, we believe that appropriate competitive atmosphere is important, as the sense of competition can effectively motivate learning and improve self-efficacy. Additionally, it is important to consider factors that influence students' flow experiences when designing and developing digital games.

However, this research is limited in that the number of male and female participants was unbalanced. Future research may have more balanced sampling so that the results can be better generalised. Also, since it concentrated mainly on the effects of gameplay modes on students' IL learning, some research issues were not covered. Thus, future studies may consider investigating them. For example, what factors place positive or negative effects on students' flow experiences in GBL, and among these factors, which ones are more influential? Additionally, the post-test of this research included only true-false and multiple-choice questions, and future researchers may consider including open-ended questions in their post-tests or asking students to apply what they have learned in IL-related projects, through which students' application of IL knowledge can be better measured.

\section{Acknowledgements}

Di Zou's work in this research has been supported by the Internal Research Grant (RG15/20-21R), The Education University of Hong Kong. Haoran Xie's work in this research has been supported by the Teaching Development Grant (102489) at Lingnan University, Hong Kong.

\section{References}

Admiraal, W., Huizenga, J., Akkerman, S., \& Ten Dam, G. (2011). The concept of flow in collaborative game-based learning. Computers in Human Behavior, 27(3), 1185-1194. https://doi.org/10.1016/j.chb.2010.12.013

American Library Association. (2000). Information literacy competency standards for higher education. University of Arizona, Association of College and Research Libraries. http://www.ala.org/acrl/standards/informationliteracycompetency

Annetta, L. A. (2010). The "I's" have it: A framework for serious educational game design. Review of General Psychology, 14(2), 105-113. https://doi.org/10.1037/a0018985

Barzilai, S., \& Blau, I. (2014). Scaffolding game-based learning: Impact on learning achievements, perceived learning, and game experiences. Computers \& Education, 70, 65-79. https://doi.org/10.1016/j.compedu.2013.08.003

Cagiltay, N. E., Ozcelik, E., \& Ozcelik, N. S. (2015). The effect of competition on learning in games. Computers \& Education, 87, 35-41. https://doi.org/10.1016/j.compedu.2015.04.001

Chen, C. H., \& Law, V. (2016). Scaffolding individual and collaborative game-based learning in learning performance and intrinsic motivation. Computers in Human Behavior, 55, 1201-1212.

https://doi.org/10.1016/j.chb.2015.03.010 
Chen, C. H., Law, V., \& Huang, K. (2019). The roles of engagement and competition on learner's performance and motivation in game-based science learning. Educational Technology Research and Development, 67(4), 1003-1024. https://doi.org/10.1007/s11423-019-09670-7

Chen, C. H., Liu, J. H., \& Shou, W. C. (2018). How competition in a game-based science learning environment influences students' learning achievement, flow experience, and learning behavioral patterns. Journal of Educational Technology \& Society, 21(2), 164-176. https://www.jstor.org/stable/10.2307/26388392

Chen, C. H., Shih, C. C., \& Law, V. (2020). The effects of competition in digital game-based learning (DGBL): A meta-analysis. Educational Technology Research and Development, 68(4), 1855-1873. https://doi.org/10.1007/s11423-020-09794-1

Chen, M. P., Wang, L. C., Zou, D., Lin, S. Y., \& Xie, H. R. (2019). Effects of caption and gender on junior high students' EFL learning from iMap-enhanced contextualized learning. Computers \& Education, 140, Article 103602. https://doi.org/10.1016/j.compedu.2019.103602

Chen, M. P., Wang, L. C., Zou, D., Lin, S. Y., Xie, H., \& Tsai, C. C. (2020). Effects of captions and English proficiency on learning effectiveness, motivation and attitude in Augmented-Realityenhanced theme-based contextualized EFL learning. Computer Assisted Language Learning, 1-31. https://doi.org/10.1080/09588221.2019.1704787

Chen, S. Y., \& Chang, Y. M. (2020). The impacts of real competition and virtual competition in digital game-based learning. Computers in Human Behavior, 104, Article 106171. https://doi.org/10.1016/j.chb.2019.106171

Chen, Y. H., \& Wang, C. H. (2018). Learner presence, perception, and learning achievements in augmented-reality-mediated learning environments. Interactive Learning Environments, 26(5), 695708. https://doi.org/10.1080/10494820.2017.1399148

Csikszentmihalyi, M. (2014). Play and intrinsic rewards. In M. Csikszentmihalyi (Ed.), Flow and the foundations of positive psychology: The collected works of Mihaly Csikszentmihalyi (pp. 135-153). Springer. https://doi.org/10.1007/978-94-017-9088-8_10

Delucia, A., Francese, R., Passero, I., \& Tortora, G. (2009). Development and evaluation of a virtual campus on second life: The case of SecondDMI. Computers \& Education, 52(1), 220-233. https://doi.org/10.1016/j.compedu.2008.08.001

Derakhshan, M., Hassanzadeh, M., \& Nazari, M. (2015). Developing information literate librarians: A study of LIS academics pedagogical approaches in the development of information literacy competencies. The Journal of Academic Librarianship, 41(6), 777-785. https://doi.org/10.1016/j.acalib.2015.08.021

DiNardo, C. O., \& Broussard, M. J. S. (2019). Commercial tabletop games to teach information literacy. Reference Services Review, 47(2), 106-117. https://doi.org/10.1108/RSR-10-2018-0066

Eow, Y. L., Ali, W. Z. B. W., Mahmud, R. B., \& Baki, R. (2010). Computer games development and appreciative learning approach in enhancing students' creative perception. Computers \& Education, 54(1), 146-161. https://doi.org/10.1016/j.compedu.2009.07.019

Fu, F. L., Su, R. C., \& Yu, S. C. (2009). EGameFlow: A scale to measure learners' enjoyment of elearning games. Computers \& Education, 52(1), 101-112. https://doi.org/10.1016/j.compedu.2008.07.004

Guo, Y. R., Goh, D. H. L., \& Luyt, B. (2017). Tertiary students' acceptance of a game to teach information literacy. Aslib Journal of Information Management, 69(1), 46-63. https://doi.org/10.1108/AJIM-08-2016-0131

Hong, J. C., Hwang, M. Y., Lu, C. H., Cheng, C. L., Lee, Y. C., \& Lin, C. L. (2009). Playfulness-base design in educational games: A perspective on an evolutionary contest game. Interactive Learning Environments, 17(1), 15-35. https://doi.org/10.1080/10494820701483615

Hsiao, H. S., Chang, C. S., Lin, C. Y., \& Hu, P. M. (2014). Development of children's creativity and manual skills within digital game-based learning environment. Journal of Computer Assisted Learning, 30(4), 377-395. https://doi.org/10.1111/jcal.12057

Hsieh, M. L., Dawson, P. H., Hofmann, M. A., Titus, M. L., \& Carlin, M. T. (2014). Four pedagogical approaches in helping students learn information literacy skills. The Journal of Academic Librarianship, 40(3-4), 234-246. https://doi.org/10.1016/j.acalib.2014.03.012

Hsu, T. C. (2017). Learning English with augmented reality: Do learning styles matter? Computers \& Education, 106, 137-149. https://doi.org/10.1016/j.compedu.2016.12.007

Hwang, G. J., \& Chang, S. C. (2016). Effects of a peer competition-based mobile learning approach on students' affective domain exhibition in social studies courses. British Journal of Educational Technology, 47(6), 1217-1231. https://doi.org/10.1111/bjet.12303 
Hwang, G. J., Zou, D., \& Lin, J. (2020). Effects of a multi-level concept mapping-based question-posing approach on students' ubiquitous learning performance and perceptions. Computers \& Education, 149, Article 103815. https://doi.org/10.1016/j.compedu.2020.103815

Jemmali, C., Bunian, S., Mambretti, A., \& El-Nasr, M. S. (2018). Educational game design: An empirical study of the effects of narrative. In Proceedings of the 13th International Conference on the Foundations of Digital Games (pp. 1-10). ACM. https://doi.org/10.1145/3235765.3235783

Johnston, N. (2010). Is an online learning module an effective way to develop information literacy skills? Australian Academic \& Research Libraries, 41(3), 207-218. https://doi.org/10.1080/00048623.2010.10721464

Kiili, K. (2005). Digital game-based learning: Toward an experiential gaming model. Internet and Higher Education, 8, 13-24. https://doi.org/10.1016/j.iheduc.2004.12.001

Kiili, K., De Freitas, S., Arnab, S., \& Lainema, T. (2012). The design principles for flow experience in educational games. Procedia Computer Science, 15, 78-91. https://doi.org/10.1016/j.procs.2012.10.060

Kollöffel, B., \& De Jong, T. (2016). Can performance feedback during instruction boost knowledge acquisition? Contrasting criterion-based and social comparison feedback. Interactive Learning Environment, 24(7), 1428-1438. https://doi.org/10.1080/10494820.2015.1016535

Koltay, T. (2011). The media and the literacies: Media literacy, information literacy, digital literacy. Media, Culture \& Society, 33(2), 211-221. https://doi.org/10.1177/0163443710393382

Kong, S. C. (2014). Developing information literacy and critical thinking skills through domain knowledge learning in digital classrooms: An experience of practicing flipped classroom strategy. Computers \& Education, 78, 160-173. https://doi.org/10.1016/j.compedu.2014.05.009

Kuo, F. R., Hwang, G. J., \& Lee, C. C. (2012). A hybrid approach to promoting students' web-based problem solving competence and learning attitude. Computers \& Education, 58(1), 351-364. https://doi.org/10.1016/j.compedu.2011.09.020

Liu, Y. C., Wang, W. T., \& Lee, T. L. (2020). An integrated view of information feedback, game quality, and autonomous motivation for evaluating game-based learning effectiveness. Journal of Educational Computing Research, 1-38. https://doi.org/10.1177/0735633120952044

Markey, K., Swanson, F., Jenkins, A., Jennings, B. J., Jean, B. S., Rosenberg, V., Yao, X., \& Frost, R. L. (2008). Designing and testing a web-based board game for teaching information literacy skills and concepts. Library Hi Tech, 26(4), 663-681. https://doi.org/10.1108/07378830810920978

Park, J., Kim, S., Kim, A., \& Mun, Y. Y. (2019). Learning to be better at the game: Performance vs. completion contingent reward for game-based learning. Computers \& Education, 139, 1-15. https://doi.org/10.1016/j.compedu.2019.04.016

Pearce, J. M., Ainley, M., \& Howard, S. (2005). The ebb and flow of online learning. Computers in Human Behavior, 21(5), 745-771. https://doi.org/10.1016/j.chb.2004.02.019

Perttula, A., Kiili, K., Lindstedt, A., \& Tuomi, P. (2017). Flow experience in game based learning: A systematic literature review. International Journal of Serious Games, 4(1), 57-72. https://doi.org/10.17083/ijsg.v4i1.151

Pintrich, P. R., Smith, D. A. F., Garcia, T., \& McKeachie, W. J. (1991). A manual for the use of the motivational strategies learning questionnaire (MSLQ). National Center for Research to Improve Postsecondary Teaching and Learning.

Plass, J. L., O’Keefe, P. A., Homer, B. D., Case, J., Hayward, E. O., Stein, M., \& Perlin, K. (2013). The impact of individual, competitive, and collaborative mathematics game play on learning, performance, and motivation. Journal of Educational Psychology, 105(4), 1050-1066. https://doi.org/10.1037/a0032688

Romero, M., Ouellet, H., \& Sawchuk, K. (2017). Expanding the game design play and experience framework for game-based lifelong learning (GD-LLL-PE). In M. Romero, K. Sawchuk, J. Blat, S. Sayago, \& H. Ouellet (Eds.), Game-based learning across the lifespan: Cross-generational and ageoriented topics (pp. 1-11). Springer. https://doi.org/10.1007/978-3-319-41797-4

Ronimus, M., Kujala, J., Tolvanen, A., \& Lyytinen, H. (2014). Children's engagement during digital game-based learning of reading: The effects of time, rewards, and challenge. Computers \& Education, 71, 237-246. https://doi.org/10.1016/j.compedu.2013.10.008

Sharples, M. (2000). The design of personal mobile technologies for lifelong learning. Computers \& Education, 34(3-4), 177-193. https://doi.org/10.1016/S0360-1315(99)00044-5

Shiue, Y. M., \& Hsu, Y. C. (2017). Understanding factors that affecting continuance usage intention of game-based learning in the context of collaborative learning. Eurasia Journal of Mathematics, Science and Technology Education, 13(10), 6445-6455. https://doi.org/10.12973/ejmste/77949 
Smith, A. L., \& Baker, L. (2011). Getting a clue: Creating student detectives and dragon slayers in your library. Reference Services Review, 39(4), 628-642. https://doi.org/10.1108/00907321111186659

Su, F., \& Zou, D. (2020). Technology-enhanced collaborative language learning: Theoretical foundations, technologies, and implications. Computer Assisted Language Learning, 1-35. https://doi.org/10.1080/09588221.2020.1831545

Sung, H. Y., \& Hwang, G. J. (2013). A collaborative game-based learning approach to improving students' learning performance in science courses. Computers \& Education, 63, 43-51. https://doi.org/10.1016/j.compedu.2012.11.019

Troussas, C., Krouska, A., \& Sgouropoulou, C. (2020). Collaboration and fuzzy-modeled personalization for mobile game-based learning in higher education. Computers \& Education, 144, Article 103698. https://doi.org/10.1016/j.compedu.2019.103698

Wang, L. C., \& Chen, M. P. (2010). The effects of game strategy and preference: Matching on flow experience and programming performance in game-based learning. Innovations in Education and Teaching International, 47(1), 39-52. https://doi.org/10.1080/14703290903525838

Wei, C. W., Kao, H. Y., Lu, H. H., \& Liu, Y. C. (2018). The effects of competitive gaming scenarios and personalized assistance strategies on English vocabulary learning. Journal of Educational Technology \& Society, 21(3), 146-158. https://www.jstor.org/stable/10.2307/26458514

$\mathrm{Wu}, \mathrm{J} ., \mathrm{Li}, \mathrm{X} .$, \& He, X. (2015). The development of story and learning driven by assessment in information literacy educational game Wisdom Town. In Proceedings of the 2015 International Conference of Educational Innovation through Technology (pp. 68-71). IEEE. https://doi.org/10.1109/EITT.2015.21

Wu, J. H., Wang, S. C., \& Tsai, H. H. (2010). Falling in love with online games: The uses and gratifications perspective. Computers in Human Behavior, 26(6), 1862-1871. https://doi.org/10.1016/j.chb.2010.07.033

Young, M. F., Slota, S., Cutter, A. B., Jalette, G., Mullin, G., Lai, B., Simeoni, Z., Tran, M., \& Yukhymenko, M. (2012). Our princess is in another castle: A review of trends in serious gaming for education. Review of Educational Research, 82(1), 61-89. https://doi.org/10.3102/0034654312436980

Yukselturk, E., Altık, S., \& Bas er, Z. (2018). Using game-based learning with Kinect technology in foreign language education course. Journal of Educational Technology \& Society, 21(3), 159-173. https://www.jstor.org/stable/10.2307/26458515

Zhang, R. \& Zou, D. (2020). Types, purposes, and effectiveness of state-of-the-art technologies for second and foreign language learning. Computer Assisted Language Learning, 1-47. https://doi.org/10.1080/09588221.2020.1744666

Zou, D. (2020). Gamified flipped EFL classroom for primary education: Student and teacher perceptions. Journal of Computers in Education, 7(2), 213-228. https://doi.org/10.1007/s40692-020-00153-W

Zou, D., Huang, Y., \& Xie, H. (2019). Digital game-based vocabulary learning: Where are we and where are we going? Computer Assisted Language Learning, 1-27. https://doi.org/10.1080/09588221.2019.1640745

Zou, D., Luo, S., Xie, H., \& Hwang, G. J. (2020). A systematic review of research on flipped language classrooms: Theoretical foundations, learning activities, tools, research topics and findings. Computer Assisted Language Learning, 1-27. https://doi.org/10.1080/09588221.2020.1839502

Zou, D., \& Xie, H. (2018). Personalized word-learning based on technique feature analysis and learning analytics. Educational Technology \& Society, 21(2), 233-244. https://drive.google.com/file/d/1GBwnHKJ5jmRFQ0GrygvEYekr4HrfnZ8H/view

Zou, D., \& Xie, H. (2019). Flipping an English writing class with technology-enhanced just-in-time teaching and peer instruction. Interactive Learning Environments, 27(8), 1127-1142. https://doi.org/10.1080/10494820.2018.1495654

Zou, D., Xie, H., \& Wang, F. (2018). Future trends and research issues of technology-enhanced language learning: A technological perspective. Knowledge Management \& E-Learning: An International Journal, 10(4), 426-440. https://doi.org/10.34105/j.kmel.2018.10.026

Zurita, G., Nussbaum, M., \& Salinas, R. (2005). Dynamic grouping in collaborative learning supported by wireless handhelds. Educational Technology \& Society, 8(3), 149-161. https://www.jstor.org/stable/10.2307/jeductechsoci.8.3.149 
Corresponding author: Di Zou, dizoudaisy@gmail.com

Copyright: Articles published in the Australasian Journal of Educational Technology (AJET) are available under Creative Commons Attribution Non-Commercial No Derivatives Licence (CC BY-NC-ND 4.0). Authors retain copyright in their work and grant AJET right of first publication under CC BY-NC-ND 4.0.

Please cite as: Zou, D., Zhang, R., Xie, H., \& Wang, F. L. (2021). Digital game-based learning of information literacy: Effects of gameplay modes on university students' learning performance, motivation, self-efficacy and flow experiences. Australasian Journal of Educational Technology, 37(2), 152-170. https://doi.org/10.14742/ajet.6682 